Est Ag 56 (2021) 5-36

\title{
La persona humana, relación religada en san Agustín
}

\author{
TARSICIO JÁÑEZ BARRIO \\ Universidad Católica Andrés Bello. Caracas
}

Resumen: Agustín de Hipona nació en el norte de África dotado de una gran sensibilidad y amor al estudio. Enamorado en su juventud de la retórica, la investigó con denuedo para brillar, al término de la misma, ganando la cátedra de Retórica de la Casa Imperial de Milán. La conversión al cristianismo le trastorna la vida y la Gracia divina hace de su esfuerzo un faro de sabiduría; de su sacerdocio y aceptación de la mitra un polemista y un apologeta incansable; de su fe en Cristo y en la Iglesia un gran intérprete de la Biblia, un valiente teólogo y un audaz buscador de Dios. Todo ello en el contexto del colapso del Imperio romano. No por azar, en su voz se ve un antecedente inspirador de la actitud moderna con que el yo se autocomprende y valora su misión en el mundo.

Pero de la misma manera que él bebe y reinterpreta fuentes previas, otros, posteriormente, beberán y reinterpretarán su palabra. Así, después de Kant, la filosofía idealista trató de acostumbrarnos a pensar que el contacto con la realidad, los hechos decisivos de la historia y la construcción del destino personal dependen solo o primero de un Yo ('sujeto' o 'subjetividad') que explora, sueña, selecciona, planifica, decide e interpreta, a solas, el sentido del mundo. Pensadores como Descartes o Hegel, tratarán de reinterpretar la experiencia cristiana y agustiniana.

Así las cosas, y dada la vigencia de san Agustín, conviene releer sus escritos para escuchar directamente de su palabra el fundamento de su experiencia, la razón de sus opciones y la articulación de su hermenéutica. Interesa, por ejemplo, ver cómo leyó a Platón y Aristóteles, cómo glosó sus conceptos y qué encontró Agustín que no estaba en el 'logos' griego. En este texto nos centramos en el concepto de "substancia" y "persona" en san Agustín, en el marco de su reflexión sobre el misterio trinitario del Dios cristiano, resaltando el influjo que va a tener en la construcción de una antropología que quiere sobrepasar la metafísica 
griega. Su posición marcará una singular relación con la filosofía y abrirá caminos ricos y exigentes a la teología. Desde aquí, se tocan y reivindican algunas cosas que san Agustín plantea tanto a la teología escolástica como a la filosofía moderna de X. Zubiri.

Palabras clave: San Agustín, Persona, Trinidad, Substancia, Modernidad, Escolástica, Religación, Psicología.

Abstract: Augustine of Hippo, endowed with a great sensitivity and love for studies was born in North Africa. Passionate with rhetoric at his younger days, he investigated it so boldly to excel in such way that at the end of it, won the chair of Rhetoric at the Imperial court of Milan. His conversion to Christianity transformed his life and the divine Grace made his effort a beacon of wisdom; with his priesthood and acceptance of the bishophood, becomes a polemist and a tireless apologist; through his faith in Christ and in the Church, a great interpreter of the Bible, a courageous theologian and a fearless searcher of God. All this happens in the context of the collapse of the Roman Empire. It is not causal that in his voice there seen exposed an inspiring antecedent of the modern attitude with which the self understands itself and values its mission in the world.

Notwithstanding, in the same way Augustine takes up and reinterprets previous sources, much later, others would drink from and reinterpret his thoughts. Thus, after Kant, idealistic philosophy tried to familiar us to think that the contact with reality, the decisive facts of history and the construction of personal destiny depend alone or primarily on an 'Ego' ('subject' or 'subjectivity') that explores, dreams, chooses, programs, resolves and interprets, by itself the meaning of the world. Likewise, philosophers like Descartes or Hegel, would try to reinterpret the Christian and Augustinian experience.

With the above background and given the validity of Saint Augustine, it is convenient to reread his writings in order to hear directly from his words the fundaments of his experience, the reason for his choices and the articulation of his hermeneutics. For example, it is interesting to see how he read Plato and Aristotle, how he glossed their concepts and, what else Augustine found which was not in the Greek 'logos'. In this study, we focus on the concept of «substance» and «person» in Saint Augustine, within the framework of his reflection on the Trinitarian mystery of the Christian God, highlighting the influence that he would undergo in the construction of an anthropology which aspires to overcome Greek metaphysics. His position will mark a unique relationship with the phi- 
losophy and will open up enriching and demanding pathways to theology. From here, some matters that Saint Augustine would raise both to scholastic theology and to the modern philosophy of X. Zubiri are dealt with and vindicated.

Key words: Saint Augustine, Zubiri, Person, Trinity, Substance, Modernity, Scholasticism, Religion, Psychology.

\section{INTRODUCCIÓN}

"Hagamos al hombre a nuestra imagen, conforme a nuestra semejanza"1. Este es el punto radical y absoluto del cual parte Agustín para todas sus reflexiones antropológicas y desde donde adquiere unidad integradora todo su pensamiento. Y lo hace porque, al descubrir que su naturaleza es mudable, se despliega desde su interior un movimiento tensional hacia Dios Verdad, Bondad, Belleza... ${ }^{2}$, fundamento ontológico de su ser, es decir, persona constituida como relación religada. El hombre interior, efectivamente, comienza descubriendo plasmada en su "mens" la relación trinitaria: "esse, intellegere, amare", expresiones de su mismo dinamismo vital. Es la "mens" el núcleo definitorio de la persona como relación consustantiva:

"Non ergo essem, Deus meus, non omnino essem, nisi esses in me. An potius non essem, nisi essem in te, ex quo omnia, per quem omnia, in quo omnia? Etiam sic, Domine, etiam sic"3. "Non essem nisi in te supra me"4. "Deus, supra quem nihil, extra quem nihil, sine quo nihil est. Deus sub quo totum est, in quo totum est, cum quo totum est. Qui fecisti hominem ad imaginem et similitudinem tuam, quod qui se ipse novit, agnoscit"s.

X. Zubiri se hace eco también de esta misma reflexión básica cuando dice: "Lo que Dios ha querido primo et per se es plasmar ad extra su propia vida trinitaria". "Plasmar que es participar de la realidad absolutamente absoluta, tiene lugar constituyendo una realidad personal relativamente

\footnotetext{
${ }^{1}$ Gn. 1,26 .

${ }^{2}$ Sol. 1,1,3; Conf. 1,1,1;10,6,9-10.

${ }^{3}$ Conf. 1,2,2; 10,27,38; In Ev. Io. 2,10-11.

${ }^{4}$ Ibíd. 10,26,37.

${ }^{5}$ Sol. $1,1,4$.
} 


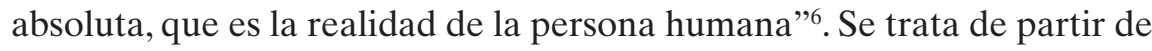
la Trinidad como fundamento que hace posible las estructuras del hombre $^{7}$. Tanto para Agustín como para X. Zubiri la visión antropológica integral no puede menos de fundamentarse en una relación de religación (teologal, que no teológica). Es aceptar como única base sólida e incuestionable aquel "Hagamos al hombre a nuestra imagen conforme a nuestra semejanza".

La trinidad de personas, como relaciones subsistentes en Dios, la contempla Agustín en la unidad de cada persona humana constituida por su triple relación de "mens et amor et notia eius", o de "memoria, inteligencia y voluntad" 10 . Por tanto, este ser relación religada define a la persona como "ser relación". Porque, cuando se dice: "En su esencia el hombre, más que ser, como atestigua la memoria que de sí tiene, es sobre todo 'ser en relación', porque tiene no en sí sino en otro el fundamento ontológico propio"11, lo que efectivamente define su condición de "ser religado" en nada empieza a ser considerado como "ser relación", en el entendido agustiniano de que "el ser relación" está incluido en su condición de ser religado. X. Zubiri nos hablaría de "relación relativamente absoluta".

${ }^{6}$ Xavier Zubiri, El problema teologal del hombre: Cristianismo, Alianza Editorial, Madrid 1999, 210.

${ }^{7}$ Ibíd. 213.

${ }^{8}$ Ya en otro lugar hemos dejado constancia del sentido agustiniano de esta posición asentada sobre el acontecimiento de la creación como la visión más razonable, en contra de las teorías del caos, azar, eterno retorno,... las cuales dejan sin sustentación el de dónde, el por qué y el quién del hombre. Cf. "La dignidad humana en San Agustín: El hombre creado a imagen y semejanza de Dios. Desde la dignidad a la dignificación”.

${ }^{9} \operatorname{Tr} .9,3-5$,

${ }^{10}$ Ibíd. 10,11-12.

${ }^{11}$ Antonio Pieretti, "Doctrina antropológica Agustiniana”, en: J. Oroz Reta - J.A. Galindo Rodrigo, El pensamiento de San Agustín para el hombre de hoy. I. La Filosofía Agustiniana, Edicep, Valencia 1998, 356. Entiende a la persona como "ser en relación", lo cual es inadecuado, porque "en relación" se puede afirmar de todo ser, pero el ser persona es una realidad distinta y específica. 


\section{POSICIÓN ARQUIMEDIANA DE LA PERSONA}

\subsection{Clasificación de la realidad}

Agustín tiene una concepción dialéctica y dinámica del hombre, más allá de su composición hylemórfica (alma-materia), que brota de una doble fuente de inspiración: de la noción platónica cristianizada de participación a modo de un haz de perfecciones recibidas de Dios y de la concepción bíblico-paulina asentada sobre el apotegma del hombre creado "a imagen y semejanza Dei Trinitatis" que refleja (plasma) el dinamismo radical de la mente (ontología vital) expresado por la memoria, la inteligencia y la voluntad. Este dinamismo radical de la mens, presente a sí misma, se resuelve en ese haz de actividades espirituales que llamamos "recordarse, conocerse y amarse"; y que no son idénticos entre sí: "aliud est memoria, aliud est intellegentia, aliud dilectio sive caritas" 12 , pero que, sin embargo, constituyen una sola y misma vida radical, una mente, una esencia: "inseparabilis vita, et una vita, et una mens et una essentia"13. De aquí su clasificación de la realidad.

La primera clasificación que hace Agustín es la del ser metafísico: "esse-essentia ("subsistentia-esse subsistens", "esse in", ser absoluto), relación-hypóstasis (habitud, "esse ad"), ser relativo-persona, y accidente (ser inhesivo). Y la ontología del ser pide una división fundamental: ser absoluto-infinito-inmutable y ser contingente limitado-mudable; ser increado y ser creado. En Dios, vida trinitaria y realidad absoluta, solo cabe la clasificación: "esse-essentia (subsistentia-esse subsistens, "esse in" y "relatio" (habitud), "esse ad", ser relativo-persona. Pues "en Dios es una misma cosa ser y ser persona (...non enim aliud est Deo esse, aliud personam esse, sed omnino idem)". Sin embargo, "si ser es término absoluto, persona lo es relativo"14. Lo relativo aquí no es accidente; solamente en

12 Tr., 15,17,28; 14,5,7. Cf. Argimiro Turrado: Intr. Gen. a las Obras Completas de San Agustín, Tom. 35, BAC, Madrid 1984, 77.

${ }^{13}$ Conf. 13,11,12; Tr. 9,11,16;10,11,18.

${ }^{14} \operatorname{Tr} .7,6,11$. Cf. "non audemus dicere unam essentiam, tres substantias; sed unam essentiam vel substantiam, tres autem personas... Cuando se nos pregunta qué son estos tres (Padre, Hijo y Espíritu Santo), tenemos que reconocer la indigencia extremada de nuestro lenguaje. Decimos tres personas para no guardar silencio, no para decir lo que es la Trinidad" (Tr. 5,9,10). 
la ontología del ser creado cabe la clasificación aristotélica: substantia (sub-stare) y accidente (ser inhesivo). "En las cosas creadas y mudables, todo lo que se predica según la substancia, se predica según los accidentes"15. "Aplicamos propiamente el concepto de sustancia a los seres mudables y compuestos"16, donde funcionan las categorías aristotélicas, porque la substancia es "sub-stare" respecto de los accidentes, y donde la relación es uno de los accidentes, adheridos-inhesivos a la substancia. Mientras que en el ser realidad-absoluta, la relación es constitutiva, y la substancia solo se puede entender como "sub-sistere", nunca como "substare" $" 17$.

Clasificación antropológica específica: Dentro de esta clasificación metafísico-ontológica general que hace Agustín, subyace esta otra clasificación específica, como partícipe necesario de aquel mismo principio: "Hagamos al hombre a nuestra imagen y semejanza", i.e., "hecho a imagen y semejanza de la Trinidad de personas". Porque si el hombre, por "ser hecho a imagen del Dios Trino", participa de la realidad y vida trinitaria, y por ser "hecho a semejanza de Dios" participa de su ser al modo de las

${ }^{15}$ Ibíd. 5,5,6, in nota 6.

16 Ibíd. 7,5,10.

${ }^{17}$ Sustantia (natura) es entendida en Agustín como subsistentia (Tr. 7,4,9; VR. 7,13). Sustancia como "sub-stare" se dice impropiamente de Dios, pero sí se dice esencia "essentia proprie" (o substantia en el sentido de esse-subsistere) (Tr. 7,5,10; 5,2,3 -esencia, de esse = ousía en griego-; 5,9,10; 7,1,1-2; 7,6,11; CD. 12,2; Ep.118,3,15; In Ev. Io. 99,5;38,10-11; Conf. 13,31,46 -Est-; S. 6,4 -"Yo soy el que soy" (essentia)-; 7,7; En in Ps. 101,(2),10). Substantia en Agustín hay que entender como "subsistencia-ousía"; no cabe entenderla como el griego entendió la "hypóstasis"; esencia y subsistencia se identifican. Por eso no se puede aplicar a Dios el término substantia (sub-stare) sino solo de modo abusivo (Tr. 7,5,10). "Essentiam dico, quae ousía grace dicitur, quam usitatius substantiam vocamus" (Ibíd. 5,8,9). "Los griegos dicen también hipóstasis, pero ignoro qué diferencia pueda existir entre ousía e hypóstasis. Ciertos escritores de los nuestros que tratan estas cuestiones en idioma heleno, acostumbran a decir mían ousían, treís hypostáseis, en latín "unam essentiam tres substantias" (Tr. 5,8,9). "Nosotros, los latinos, decimos tres personas y una esencia” (Ibíd. 7,4,9). Es, pues, más razonable hablar de tres personas en Dios que de tres sustancias" (Ibíd. 7,5,10). "Decimos tres personas por no guardar silencio" (Ibíd. 5,9,10; 7,4,7-9). Hecha esta salvedad, "se puede decir tres substancias o tres personas, sin diversidad de esencia (Ibíd. 8,1proem). Hubo diverso sentir entre los Padres en el uso de una terminología unitaria. Hypóstasis en sentido etimológico quiere decir "substancia", pero ya desde el Concilio de Constantinopla I (381) se proclama la equivalencia de los términos "persona e hypóstasis (prósopon)", y ratificado por el Concilio de Calcedonia (451). 
demás criaturas, y ningún otro ser creado goza de esta doble condición, i.e., que si ninguna otra criatura goza conjuntamente de lo permanente e inmortal de Dios y de lo contingente y mortal del ser creado, entonces habrá que clasificar al hombre como un verdadero "metaxy" o realidad intermedia, dado que solo él ha sido creado "a imagen y semejanza de la trinidad": "Hagamos al hombre...". Por consiguiente, las categorías aplicadas a Dios se podrán aplicar, si bien según lo pide la condición de "a imagen de Dios", a la realidad humana, y también las categorías correspondientes al resto de las cosas creadas, según lo exige la condición "a semejanza de Dios"18.

Desde esta base ontológico-antropológica, como punto arquimediano ${ }^{19}$ según el cual participa del ser superior y del inferior, centra Agustín su mirada en el interior del hombre y contempla que su "mens", verdadero "metaxy", encarna lo más constitutivo y mejor de la persona humana, su condición relacional trinitaria: "la memoria, la inteligencia y la voluntad", las cuales lejos de ser considerados como actos de la persona, del yo, son dinamismo consustantivo de la propia "mens", porque sin los cuales no hay mens posible ni relación trinitaria alguna. Así en la persona se establece una dialéctica entre "mens" y "haec tria", donde "haec tria" son relaciones reales y, ciertamente, no son la "mens-sustantiva", pero sí le son consustantivas a la mens, porque son dinamismo y actividad de la "mens", no meros actos o accidentes ${ }^{20}$. Sin "haec tria", que son relación, no hay "mens", y sin mens no hay "haec tria"21. "Tria relative, unum es-

${ }^{18}$ Aquí, desde el hombre es desde donde cabe catalogar y justipreciar las verdades, bienes y valores: El Bien Sumo (Supremo), el bien intermedio donde se encuentran los bienes muy grandes (grandes), los medianos y menores; y los bienes inferiores o ínfimos (LA.2,17-19; Nat. b. 20 y 26; VR. 18-19; Tr. 8,3,4-5; CD. 22,24; cf. S. 21,3; 80,7;299; D. 1;33,35; C. 13; De b. coniu. 19,22).

${ }^{19}$ Así también lo sitúa la filosofía del genial gallego Ángel Amor Ruibal: "El hombre aparece entre Dios y el cosmos, como centro de esta encrucijada" (cit. por Andrés OrtizOsés, o.c. 294).

${ }^{20} \operatorname{Tr}$. 9,5,4-7.

${ }^{21}$ La relación es para X. Zubiri y M. Heidegger solo algo externo o adveniente extrínsecamente (X. Zubiri, Estructura dinámica de la realidad,56). Pero la relatividad no implica que sus términos sean elementos constituidos, como supone X. Zubiri. Sin embargo, en el pensamiento agustiniano, "haec tria" tiene el sentido que para Amor Ruibal tienen las relaciones, las cuales son siempre "relaciones-de-elementos" y los elementos son siempre “elementos-en-relación” (cf. Andrés Ortiz-Osés: o.c., 277). No hay prioridad entre elemen- 
sentialiter"22. La "mens" en Agustín más propiamente que substancia tiene el carácter de subsistencia (essentia).

\subsection{La persona humana es dinamismo relacional plasmado de la vida trinitaria}

La clasificación metafísica del ser nos descubre, en primera instancia, el dinamismo constitutivo de la divinidad con sus tres relaciones reales subsistentes, i.e., personas en Dios; y en segundo lugar, nos descubre también la plasmación de esa vida relacional en el dinamismo de la "mens" constituido por su triple relación: memoria, entendimiento y voluntad. La realidad humana es dinámica particionera del dinamismo relacional de Dios.

La esencia (essentia-esse) en su aspecto dinámico, como principio de actividad, se llama "natura" de "nasci". La misma realidad esencial de Dios, por sí misma es dínamis efectiva, con subsistencia perfecta ${ }^{23}$. El dinamismo de la vida trinitario se plasma en el dinamismo vital de la persona humana. "Dios no es un Dios de muertos, sino de vivos" (Mt 22,32-33). En estos conceptos se descubre la dialéctica agustiniana sobre Dios y sobre la persona humana. La realidad de Dios es unidad dinámica de vida en la trinidad de personas. "La unidad de Dios es dinamismo"24. "La razón nos dice que la esencia divina es pura dinamis, que tiene por objeto su conocimiento y su $\operatorname{amor}^{25}$. Dios es vida trinitaria, siempre dinámico y siempre inmutable: Vida, verdad, bondad, belleza, amor, "pulcritudo tam antiqua et tam nova" ${ }^{26}$. Siempre activo y eternamente estable.

La realidad del hombre es la unidad dinámica de la "mens" en la trinidad de sus relaciones: memoria, entendimiento y amor (voluntad). "Porque yo soy, y conozco, y quiero: soy esciente y volente, y sé que soy y quiero, y quiero ser y conocer. Vea, quien pueda, por tanto, estas tres

tos y relaciones; se da un "elemental correlatismo"; el todo y las partes se coimplican mutuamente (Ibíd. 294). Lo mismo vale en Agustín para quien "existe igualdad entre el todo y la parte", porque "haec tria" si son perfectas son iguales y de modo maravilloso inseparables entre sî" (Tr. 9, 4-5; 10,11,18).

${ }^{22} \operatorname{Tr} .9,5,8 ; 10,10-11 ; 10,11,17-18 ; 10,16-18 ; 15,21,40 ; 15,27,50$.

${ }^{23}$ Cf. L. Arias, "Introducción” al De Trinitate, 41.

${ }^{24}$ X. Zubiri, El problema teologal, 111.

${ }^{25}$ L. Arias: a.c. 43.

${ }^{26}$ Conf. 10,27,38. 
cosas: cuán inseparable sea la vida, siendo una la vida, y una la mente, y una la esencia; y cuán, finalmente, inseparable de ella la distinción, no obstante que existe la distinción"27. "Yo era el que quería y el que no quería, yo era. Mas porque no quería plenamente ni plenamente no quería, por eso contendía conmigo,... no mostraba, sin embargo, la naturaleza de una mente extraña (nec tamen ostendebat naturam mentis alienae), sino la pena de la mía"28.

El hombre es vis -fuerza interior-, "id est vis mea, qua id agebam" 29 , dinamismo constitutivo:

"Magna ista vis est memoriae, magna nimis... Et vis est haec animi mei atque ad meam naturam pertinet, nec ego ipse capio totum quod sum"30; inquietud de infinito, de amor a la verdad, al bien, a la felicidad", "hasta descarsar en Dios"32. "Cum ipsa vis seminum, quos numeros habet, quam vivaces, quam efficaces,...”33, “... accipiens omnes numeros eorum quos per tempora exsereret secundum suum genus... "34, “...gestat immensa ista capacitas memoriae meae..." "35. "Transibo et hanc vim meam, quae memoria vocatur,... transibo et istam vim meam..."36.

Por donde se ve que el gozne innovador de Agustín pilota sobre "la relación" como potencia vital en su concepción del dinamismo de la Trinidad de las personas divinas, donde la relación es realidad subsistente, "aun-

\footnotetext{
${ }^{27}$ Ibíd. 13,11,12.

${ }^{28}$ Ibíd. 8,10,22.

${ }^{29}$ Ibíd. 10,40,65.

${ }^{30}$ Ibíd. 10,8,15; 10,17,26.

31 Ibíd. 10,22-23.

32 Ibíd. 1,1,1;13,9,10.

${ }^{33}$ Ep. 137,3,10.

${ }^{34}$ Gen.ad litt. 5,5,14.

${ }^{35}$ Conf. 10,9,16.
}

${ }^{36}$ Ibíd.10,17,26. Cf. $L A .2,8 ; 3,1$ (el movimiento le viene al alma de sí misma). La potencia espiritual del alma la entiende como virtud, no como extensión o cuantidad material: "memoria contineat, cum sit ipse (animus) nullius quantitatis; mira quaedam vis est, quam ex iis quae a nobis comperta sunt, quantum inest ingenio tuo luminis, animadvertere potes" (Quant.an. 14,23), “....sed maiorem quamdam vim peritior quam imperitior habere ad agendum” (Ibíd. 19,23), “...nisi vis quamdam sentiendi,...?. Sed ille sensus, cuius magna vis est, potest discernere; atque eo facilius quod anima belluarum magis corpori affixa est... Humana vero anima per rationem atque scientiam, de quibus agimus, quod sunt ista longe praestantiora sensibus" (Ibíd. 28,54). 
que muy distinta la trinidad dinámica de la persona humana, donde sus relaciones reales se llaman: memoria, entendimiento y voluntad", y "cuya consistencia óntica es tan evidente como la del espíritu (mens)"37.

Agustín "coloca el concepto metafísico de "relación" en el corazón de su discurso para conciliar en Dios la unidad de naturaleza y la trinidad de personas, esto es, para explicar cómo en una esencia única subsisten cada una de las tres personas divinas. Insiste en que las personas divinas (en Dios) son relaciones reales subsistentes. Transformó así el concepto formal de persona divina (contra los arrianos) en concepto "relacional". Aplicó también a los seres humanos ese mismo concepto "relacional"38. "El De Trinitate, dice De Simeone, no contiene explícitamente que el ser humano sea una persona, pero sostiene que los seres humanos están constituidos en personalidades morales mediante sus relaciones... con Dios, el prójimo y el propio yo; su teoría del amor lo lleva más allá de los límites tradicionales (de la doctrina del yo como substancia). Agustín encuentra la vida verdadera de los individuos humanos en la unidad de (las potencias) "haec tria": en la "mens-ego", la memoria, inteligencia y voluntad gozan de unidad de modo analógico a la unidad tripersonal de Dios"39.

Con todo esto por delante, este autor afirma: "Sin embargo, Agustín en modo alguno es el descubridor filosófico de la "persona" con los perfiles doctrinales de hoy día... La precisión ontológica del concepto de "persona" tuvo que esperar hasta el siglo sexto cuando apareció Boe-

${ }^{37}$ L. Arias, Intr. al De Trinitate. Obras Completas de San Agustín, Tom. V, BAC, Madrid 1985, 65. Es altamente sorpresivo que no se aluda para nada al concepto de persona como relación en los diversos estudios (artículos) de la obra dirigida por los agustinos recoletos, J. Oroz Reta - J.A. Galindo Rodrigo, El pensamiento de San Agustín para el hombre de hoy. I. Filosofía Agustiniana, Edicep, Valencia 1998. Cosa muy extraña también que el Diccionario de San Agustín [en adelante DSA], no hable expresamente ni una palabra de la "persona como relación. ¿Cómo se puede hablar de la mens-persona", hecha con sus "haec tria" (mens-memoria, inteligencia y amor-voluntad), "a imagen de la Trinidad", sin darle importancia a su condición relacional? ¿Es que Agustín no tiene el mérito indiscutible de ser el primero que habla de la persona como relación, revolucionando (innovando) el concepto de persona? (cf. J. Ratzinger).

${ }^{38}$ Rusell J. De Simeone, “Dios Uno, Dios Trinidad”, en: El pensamiento de San Agustín para el hombre de hoy. II. Teología Dogmática, Edicep, Valencia 2005, 204-206 (187-237).

${ }^{39}$ Ibíd. 204-5. 
cio" ${ }^{40}$. Pero tenemos que decir que esto, sin duda, más bien desvió la verdadera concepción de persona, porque esta no es tanto sustancialidad ontológica cuanto existencialidad antropológica relacional. De Simeone anhela olvidar la tesis agustiniana de la relación en favor de la boeciana y escolástica esencialistas. Supone que es un retroceso cuando, precisamente, la moderna antropología humanista y cristiana no hace otra cosa que desarrollar el núcleo agustiniano que concibe la persona humana como relación constitutiva, y no solo como "personalidad moral" consecuencia de aquella relación. Así encontramos que "Agustín sea el descubridor filosófico de la persona con los perfiles doctrinales de hoy día", según lo constatan escritores modernos como: E. Mounier, G. Marcel, M. Nédoncelle, P. Ricoeur, L. Lavelle, N. Berdiaef, M. Scheler, A. Brunner, J. Ratzinger.

Afirma Joseph Ratzinger: "Hay que criticar como inaceptable el concepto de persona de Boecio que se impuso en la filosofía occidental... Ricardo de S. Víctor ya vio correctamente que, en la comprensión teológica, la persona no descansa en el plano de la esencia sino en el de la existencia, que la filosofía aristotélico-tomista había reducido exclusivamente al plano de la esencia”. Desarrolló un concepto de persona tomado plenamente del cristianismo, definiéndola como "spiritualis naturae incommunicabilis existentia" ${ }^{41}$. Ser persona para Duns Scoto es estar instalado en la soledad: "ad personalitatem requiritur ultima solitudo, sive negatio dependentiae actualis et aptitudinalis". La define, pues, como se advierte en la tradición agustiniana, negativamente por la "independencia e incomunicabilidad" ${ }^{42}$.

"Para una verdadera ontología de la persona, incluso en una mejor línea agustiniana, cabe afirmar que persona es, esencialmente, un especial modo de ser-en-relación. La persona es "una relación substancial o, también, una substancia en relación" ${ }^{43}$. El pensamiento agustiniano constata que la persona es una subsistencia relacional, o mejor, una relación subsistente. "San Agustín trayendo a luz la idea de relación real, trajo a luz el

\footnotetext{
${ }^{40}$ Ibíd. 205-6.

${ }^{41}$ J. Ratzinger, Palabra en la Iglesia. Sígueme, Salamanca 1976, 174-75.

${ }^{42}$ José Rubén Sanabria, o.c., 242-43.

${ }^{43}$ A. Brunner, La personne incarnée, Vrin, Paris 1947, 226. Agustín entendía la substancia más bien como "subsistencia".
} 
fenómeno de la persona, aclarando definitivamente lo que ha de ser la persona: no una substancia que se cierra a sí misma, sino el fenómeno de la relación total... El hombre se constituye por la relatividad hacia el otro. El hombre es el ser de la relatividad. Es tanto más él mismo cuanto más total y directamente llega esa relatividad a su meta definitiva, a la trascendencia" 44 .

"El hombre, por su mente imagen de Dios, es relación subsistente" ${ }^{45}$, por la vía de la analogía que, con su triple relación o habitud (memoria, entendimiento y voluntad), conforma el núcleo del dinamismo humano de la persona. Aclaramos que "la relatividad hacia el otro" ha de ser entendida como "relación hacia el Otro (Dios), hacia el yo o sí mismo y hacia los otros, porque es hechura constitutiva: "a imagen de las Personas en Dios"46. Agustín no concibe el ser "a imagen de Dios" sino como realidad dinámica. El espíritu humano (mens-yo) no puede separarse de sus actividades, es su actividad. Pues por "ser relación definitoria", en cuanto tendencialidad (respectividad), no depende de que haya otros yos temporalmente existentes "de facto", aunque exige y reclama que existan. "Los seres humanos están destinados para la relación que puede darse como posibilidad o como realidad" ${ }^{47}$.

\section{POLÉMICA SERVIDA EN UN TRIPLE CAMPO INTERPRETA- TIVO}

Partiendo, sin embargo, del dinamismo constitutivo, se presenta una polémica servida en triple campo interpretativo: escolástico-medieval (substancialista), psicológico (moderno), y zubiriano,

${ }^{44}$ J. Ratzinger, o.c., 170-71 y 178.

${ }^{45}$ Tr. 7,6,12; cf. J. Rubén Sanabria: o.c., 253.

${ }^{46} D S A, 87$. Pues por "ser relación definitoria", en cuanto tendencialidad (respectividad) no depende de que haya otros yos temporalmente existentes, "de facto", aunque exige y reclama que existan. "Los seres humanos están destinados para la relación que puede darse como posibilidad o como realidad" (Tr. 14,8,11; cf. DSA, 89).

$47 \operatorname{Tr} .14,8,11$; cf. $D S A, 89$. 


\subsection{Interpretación escolástica substancialista}

Esta interpretación parte de una concepción substancialista, para la cual existe una distinción real entre el alma y sus potencias, y por tanto hay que darle el sentido de "inherencia substancial" y no de identidad y potencias $^{48}$. La visión dinámica y unitaria de la vida radical del hombre que Agustín tiene no la pudieron entender ya los escolásticos, ni siquiera san Buenaventura y santo Tomás, cuando trataban de meditar el pensamiento agustiniano referido a la "imago Dei en el hombre". Y, sin embargo, es una parte fundamental de la antropología de Agustín ${ }^{49}$.

Esta interpretación distingue la primera trinidad agustiniana: "mens, amor et notitia eius", de la segunda trinidad -evidentior trinitas-: "memoria, intellegentia, voluntas". Tal distinción es acertada, a tenor de los mismos textos. No encontramos tan acertado, porque contraviene textos de evidente claridad, deducir que en la primera trinidad su "amor et notia eius" son actos o hábitos, cuando Agustín nunca los menciona como tales actos (hábitos) en estos textos ni en su contexto, y porque el propio Agustín afirma que "haec tria": "mens, amor et notitia eius, tria quaedam sunt" y las tres son unidad; y si son perfectas, son iguales"50: "Quomodo autem illa tria non sint eiusdem substantiae, non video; cum mens ipsa se amet, atque ipsa se noverit... Unius ergo eiusdemque essentiae necesse est hacec tria sint"51. "Haec tria unum atque una substantia"52.

Así mismo, san Buenaventura y santo Tomás atribuyen indebidamente a un conocimiento por actos reflejos la noción (conocimiento) preconceptual agustiniana de la primera trinidad, como distinta de la segunda. No cabe identificar la orientación de la mente hacia Dios con el repliegue de la mente sobre sí misma, dice san Buenaventura. Y concluye en línea escolástico-tomista: en la primera trinidad hay un hábito o un acto; en la segunda, una sustancia ${ }^{53}$. Dice santo Tomás: "Ergo et semetipsam per se ipsam novit, quoniam est incorporea. Nam si non se novit, non

${ }^{48}$ L. Arias, "Introducción general” al De Trinitate, en: Obras Completas de San Agustín, Tom. V, BAC, Madrid 1985, 58.

${ }^{49}$ Argimiro Turrado: a.c., 77.

${ }^{50} \operatorname{Tr} .9,4,4$.

${ }^{51}$ Ibíd. 9,4,7.

${ }^{52}$ Ibíd. 9,1,2,18.

${ }^{53}$ San Buenaventura: In I Sent. d. 3 p.2 a.2.q. 1, cit. L. Arias: a.c., 61. 
se amat" ${ }^{54}$. Aquí se habla de un amar y conocer reflejos. Santo Tomás interpreta este texto en clave aristotélica: "Non ergo per essentiam suam, sed per actum suum se cognoscit intellectus noster" 55 , y lo relaciona con el otro texto agustiniano: "sed intuemur inviolabilem veritatem, ex qua perfecte, quantum possumus, definiamus, no qualis sit uniuscuiusque hominis mens, sed qualis esse sempiternis rationibus debeat" ${ }^{56}$. Pero el sentido de estos dos textos hay que situarlo en niveles distintos. El primero se refiere al conocimiento de sí (intuición), o noción preconsciente (preconceptual) por la cual siempre y necesariamente "la mente se conoce y se ama a sí misma" por intuición, y no como conocimiento reflejo, o como acto (hábito), porque es imposible un desconocimiento absoluto del $\mathrm{yo}^{57}$.

"He aquí, yo que busco, cuando amo algo existen tres cosas: yo, lo que amo y el amor; la mens y el amor son un espíritu, el amor y lo que se ama, son dos realidades que forman una cierta unidad, y ambas dicen relación mutua (ad invicem referuntur)" 58 . "Ipsa mens et amor et notitia eius" son como tres cosas, y las tres son unidad; y si son perfectas son iguales" ${ }^{59}$. Y el segundo se refiere a la mente contemplando la inconmutable verdad, no en lo que es la mente de cada hombre sino lo que debe ser en las razones eternas. "Lo que la mente contempla, según esta visión, en las razones eternas, es aquella realidad que puede intuir toda mente racional (rationalis mentis intuitu)... Con la mirada de la mente (visu mentis aspicimus) en aquella eterna verdad, forma y modelo de nuestro ser y de cuanto, en nosotros o en los cuerpos, obramos al actuar según la verdadera y recta razón; por ella concebimos una noticia verdadera de las cosas" $"$.

Con parecida mentalidad se expresa el P. Luis Arias en su "Introducción General" al De Trinitate: "En la trilogía de la primera trinidad: "mens,

${ }^{54} \operatorname{Tr} .9,3,3$.

55 S. Th. 1,q. 87, a. 1 c,

${ }^{56} \operatorname{Tr} .9,6,9$.

${ }^{57}$ Ibíd. 10,3-4; 14,6,9. Pues una cosa es conocer y otra pensar; no confundamos en Agustín el "noscere-scire-intellegere-sapere" con el "cogitare" (pensar-reflexionar) a lo cartesiano. El pensar siempre es reflejo, aunque sea inconsciente por rutinario (Tr. 10,4,6; 14,6-7; 12,2,2; 15,21,40; Conf. 10,11,18; cf. De Simeone: a.c., 219).

${ }^{58}$ Ibíd. 9,2,2.

${ }^{59}$ Ibíd. 9,4-5.

${ }^{60}$ Ibíd. 9,6-7. 
amor et notia eius' expresan una relación manifiesta. Y si el conocimiento y el amor se identifican con la esencia del alma, imposible sería percibir la oposición relativa. Para que exista la imagen de la Trinidad en el alma se precisan tres realidades distintas por su oposición relativa con unidad de esencia. Tres realidades en una esencia" ${ }^{61}$. Pero el pensamiento de Agustín no percibe imposibilidad alguna que una misma esencia esté constituida por tres relaciones reales. Y no la percibió porque su concepto de substancia es distinto del de la escolástica ${ }^{62}$. ¿Acaso en la vida trinitaria es imposible admitir la unidad de esencia con la trinidad de relaciones reales y, por añadidura, estas subsistentes? Porque no hay imposibilidad conceptual alguna en que una y misma vida-naturaleza (esencia) sea considerada bien en sí misma o bien en su dinamismo relacional. Mente, conocimiento y amor, tres realidades que son una sola cosa, vida, esencia. Y existen entre ellas relaciones recíprocas ${ }^{63}$ y distintas, pues la memoria no es la voluntad ni esta el entendimiento. La naturaleza de la mente se define por su dinamismo o capacidad dinámica auto-reflexiva e interrelacionada de "recordar, entender y amar" ${ }^{\prime 4}$. Hay aquí una concepción dialéctica de la persona.

\subsection{Interpretación psicológica}

Interpretación que se atiene solo a algunos textos agustinianos en los que claramente se afirma la igualdad (¿identidad?) entre el alma (menssujeto) y "haec tria". La gran mayoría de los psicólogos de nuestro tiempo, con M. Schmaus a la cabeza, consideran como genuinamente agustiniana la tesis de la identidad del alma y sus potencias ${ }^{65}$ :

"Con razón dijimos que estas tres cosas cuando son perfectas, son, en consecuencia, iguales. $Y$ si somos capaces de verlas, nos damos al mismo tiempo cuenta que estas cosas existen en el alma, y cual si ovilladas estuviesen, se desenvuelven y se dejan percibir y numerar, no como accidentes

${ }^{61}$ L. Arias, a.c., $58 \mathrm{~s}$.

${ }^{62}$ De Simeone, a.c., 218: Agustín elaboró una teoría de la sustancia relacionada consigo misma y formuló una teoría de la conversión de la mente hacia sí misma. Para él "substantia (esencia subsistente)" es equivalente a "natura, essentia, ousía)" (VR. 7,13; Mor. Eccl. cath. et manich. 2,1; Tr. 2,18,34-35; CD. 12,2).

${ }^{63} \operatorname{Tr} .15,3,5$.

${ }^{64}$ Ibíd. 14,8,11; CD. 11,26; Conf. 10,10,16;13,11,12.

${ }^{65}$ L. Arias, a.c., 58. 
de un sujeto, como el color y la figura. Luego el amor y el conocimiento no radican en la mente como en un sujeto, sino que son, al parigual de la mente, sustancia; pues, aunque tengan un sentido de mutua relación, en sí son sustancia”66. "La mente o el espíritu no son términos relativos, como tampoco lo son los hombres" ${ }^{67}$.

Pero los textos agustinianos nos llevan a considerar la dialéctica real de la "mens et haec tria", tanto en sí mismas, como en sus relaciones. En sí mismas consideradas, cada una es una vida, una substancia (esencia) y todas son una sola vida, una sola substancia (esencia); sin embargo "haec tria” en cuanto tales, dicen recíproca e intrínseca relación real:

"En aquellas tres realidades, cuando la mens se conoce y se ama, subsiste la trinidad sin mezcla ni confusión: la mente, la noticia y el amor. Y si bien cada una tiene en sí subsistencia, mutuamente todas se hallan en todas, ya una en dos, ya dos en una. Y, en consecuencia, todas en todas. Cada una de estas tres realidades tiene subsistencia propia (existe en sí misma), son de modo maravilloso inseparables entre sí, y no obstante todas juntas son una vida, una esencia. Se distinguen entre sí porque media en ellas una oposición relativa y se verifica entre ellas una circumincesión"68. Sin embargo, "cuando son perfectas, son iguales"69. "Cuando todas y cada una mutuamente se comprenden, existe igualdad entre el todo y la parte, y las tres son unidad: una vida, una mente, una esencia". "Haec igitur tria, quoniam non sunt tres vitae, sed una vita; nec tres mentes, sed una mens; consecuenter utique nec tres substantiae sunt, sed una substantia. Memoria quippe quae vita et mens et substantia dicitur, ad se ipsam dicitur: quod vero memoria dicitur, ad aliquid relative dicitur". Dígase lo mismo de la inteligencia y de la voluntad. "Vita est autem unaquaeque ad se ipsam, et mens, et essentia. Quocirca tria haec eo sunt unum, quo una vita, una mens, una essentia” Son tres sus relaciones recíprocas, y si no fueran iguales no se comprenderían mutuamente: memoria, intellegentia, voluntas, no son tres vidas, sino una vida; ni tres mentes, sino una mente"70.

\footnotetext{
${ }^{66}$ Ibíd. 9,4,5.

${ }^{67}$ Ibíd. 9,4,6.

${ }^{68}$ Ibíd. 9,5,8.

${ }^{69}$ Ibíd. 9,4,5.

${ }^{70}$ Ibíd. 10,11,18.
} 


\subsection{Interpretación zubiriana.}

En la dialéctica agustiniana, entre "mens-yo" y "haec tria", no se puede hablar de que "haec tria" se reduzcan a actos o hábitos (accidentes), como entiende X. Zubiri, porque no se trata de una concepción antropológica hylemórfica (substancialista) dualista, al modo aristotélico-escolástico, en la cual la naturaleza (substancia) es invariable-fija, ni tampoco al modo cartesiano, donde la "res extensa" y la "res cogitans" son dos sustancias completas unidas ${ }^{71}$. Sin embargo, en una antropología holística, como la de Agustín, que con su dinamismo vital busca una unidad integradora entre las diversas dimensiones o niveles de la persona humana y cuya realidad dialéctica la estructuran "mens et haec tria"72, no cabe tal apreciación. X. Zubiri se detiene solamente a reflexionar basado en el texto famoso: "Quod breviter dici potest: Ego per omnia illa tria memini, ego intellego, ego diligo, qui nec memoria sum, nec intellegentia, nec dilectio, sed haec habeo. Ista ergo dici possunt ab una persona, quae habet haec tria, non ipsa est haec tria" ${ }^{\text {"73. }}$

El carácter intrínseco de sus propiedades prueba que son obra conjunta de toda la "mens" y no inhesivas o inherentes de la substancia, como expresa Ma. Del Carmen Dolby ${ }^{74}$. Haec tria": memoria, inteligencia y amor, son mías, no suyas; y lo que obran no lo obran para mí, sino en mi favor, o mejor dicho, soy yo el que por medio de ellas actúo. Recuerdo por mi memoria, comprendo con mi inteligencia, amo con mi voluntad... Soy yo el que conozco, el que recuerdo y el que amo..." ${ }^{75}$.X. Zubiri desvía el pensamiento agustiniano por la vía del "yo-ego" partiendo de una doble consideración: que el recordar, entender y amar ("la memoria, el entendimiento y la voluntad") son meros actos (hábitos); y que hay una doble

${ }^{71}$ Argimiro Turrado, "Introducción General" al tomo 35 de las Obras Completas de San Agustín (Escritos antipelagianos -3-, 70. Pedro Laín Entralgo, Qué es el hombre. Evolución y sentido de la vida (Premio Internacional de Ensayo Jovellanos 1999), Ed. Nobel, Oviedo 1999, 174-76. José Antonio Galindo Rodrigo, “Teoría del conocimiento”, en: J. Oroz Reta - J.A. Galindo Rodrigo, El pensamiento de San Agustín para el hombre de hoy. I. La filosofía Agustiniana, Edicep, Valencia 1998, 414-17 (403-470).

72 Argimiro Turrado, a.c., $71 \mathrm{ss} ;$ cf. $D S A, 87$.

${ }^{73}$ Tr. 15,22,42; cf. X. Zubiri, Sobre el hombre, 106 ss.

${ }^{74}$ Ma. Del Carmen Dolby, El hombre es imagen de Dios. Visión antropológica de San Agustín. EUNSA. Pamplona 2002, 171.

${ }^{75}$ Tr. 15, 22,42; Conf. 8,10,22-24. 
confusión en el texto de Agustín: entre el yo y sus "haec tria", y entre "persona" y "naturaleza". X. Zubiri comete una triple imprecisión lógica: a) suponer que el yo-sujeto de Descartes se corresponde con el agustiniano y decir, al mismo tiempo, que tal concepto de sujeto jamás lo hubiera aceptado Agustín, donde "haec tria" es la naturaleza poseída y la "mens" el yo posidente; b) suponer que el concepto de "naturaleza y de persona" es el mismo aristotélico-escolástico; y c) afirmar que la diferencia entre "mens et haec tria" se difumina, cuando de modo constante, pero dentro de una dinámica tensional se afirma su diferencia.

Este texto (Tr. 15, 22,42), según lo interpreta X. Zubiri, afirma la diferencia entre lo que tengo y el yo que yo soy. El conjunto de todo lo que tengo, las facultades (sic), cuya unidad intrínseca y radical es lo que se llama naturaleza. Lo otro es la persona. Se afirma por tanto la diferencia entre persona y naturaleza, como una diferencia entre "posidente" (la persona, que es un "ego, un yo") y lo poseído-posesión (la naturaleza). "Esta idea va a ser decisiva. En el orto de la filosofía moderna, Descartes nos dirá que lo esencial del hombre es precisamente ser un ego. Pero que dando un tercer paso sobre los dos, de san Agustín completará la idea de este diciendo que el "yo es sujeto", cosa que jamás dijo Agustín. Este yo como sujeto es un puro yo, no es el sujeto psicobiológico, y aunque lo fuera, las estructuras psicobiológicas son, a lo sumo, las condiciones o instrumentos intrínsecos con que el yo-sujeto ejecuta física y empíricamente sus actos. Aplicada esta idea a nuestro problema, resultará que el yo posidente en que la persona consiste va a ser un sujeto posidente, y la naturaleza será la posesión de aquel sujeto puro, de aquella persona"76.

Y continúa Blanca Castilla, parafraseando a X. Zubiri: "Efectivamente hay una diferencia entre el yo y sus facultades. Pero esta diferencia se difumina al precisar en qué consiste esa diferencia. En efecto el yo considerado como sujeto al estilo de como lo entendía Descartes, como una res diversa del resto de su entidad, pasa a ser algo vacío" 77 . "Mantenida con

${ }^{76}$ X. Zubiri, o.c., 107 (La persona como forma de realidad: personeidad).

${ }_{77}$ Blanca Castilla, Noción de persona en Xavier Zubiri. Una aproximación al género, Rialp, Madrid 1996, 151. Pero en modo alguno el concepto que tiene Descartes de sujeto es aceptado por Agustín. Cf. José Antonio Galindo Rodrigo, “Teoría del conocimiento”, en: J. Oroz Reta - J.A. Galindo Rodrigo, El pensamiento de San Agustín para el hombre de hoy. I. Filosofía Agustiniana, Edicep, Valencia 1998, 415-19 (405-470). 
todo rigor la noción de la persona como un sujeto distinto realmente de su naturaleza, tamquam res et res, queda volatilizado el yo personal. Esto no puede ser. Es el yo personal quien ejecuta sus actos"78. En este caso para que el yo pueda ejecutar sus actos no podrá ser algo completamente vacío. Necesita tener alguna característica, alguna estructura intrínseca: en este caso se vuelven a introducir en el yo todas sus facultades y desaparece la diferencia entre persona y naturaleza"79. En conclusión, la persona no se descubre ni en los actos ni en la distinción entre sujeto y naturaleza. Vemos, por tanto, que ni la consideración de sus actos, ni la del yo, sujeto de ellos, sirve últimamente para caracterizar lo que es ser persona. Es que "persona no es un carácter primariamente operativo, sino constitutivo"80.

Pero a esta crítica que se hace de Agustín le falta cotejar el texto de marras, con otros pasajes como algunos de los siguientes de la misma obra agustiniana: "Haec tria in sua mente naturaliter divinitus instituta quisquis vivaciter perspicit, et quam magnum sit in ea, unde potest etiam sempiterna immutabilisque natura recoli (recordar), conspici (contemplar), concupisci (desear, amar)" "\$1, descubriendo así la imagen de la trinidad soberana. Texto carente de sentido si reducimos a meros actos el "recordar, contemplar y amar", pues ¿cómo podría cualquiera y en cualquier momento ver (perspicit) vigorosamente "haec tria" en su mente? "Encontramos una trinidad en el hombre, i.e., mentem, et notitiam qua se novit, et dilectionem qua se diligit" ${ }^{\prime \prime 2}$. Estas tres realidades, ciertamente están en el hombre, no son el hombre, no son todo el hombre, como la propia mente no es todo el hombre, como el cuerpo no es todo el hombre, pero no por eso dejan de ser constitutivas del hombre, ni implica que estén de modo "inhesivo en la mens como en un sujeto". Ambas opciones militan fuera de la mente agustiniana.

Efectivamente aquí "la memoria, el entendimiento y el amor" expresan la actividad de la mens, del yo, como capacidad, y no los actos de esa triple realidad. "A la persona humana le competen en propiedad sus acti-

${ }^{78}$ X. Zubiri, o.c., 108.

${ }^{79}$ Blanca Castilla, o.c., 151; X. Zubiri, o.c., 109.

${ }^{80}$ X. Zubiri, "El hombre, realidad personal”, en Siete ensayos de antropología filosófica, 77.
${ }^{81} \operatorname{Tr} .15,20,39$.
82 Ibíd. 15,6,10. 
vidades y sus pasividades": "quod agunt et quod aguntur" (san Agustín) ${ }^{83}$. El mismo X. Zubiri afirma que hay que distinguir entre "dinamismo-acción-actividad" y "acto-hábito" 84 . Apreciación zubiriana aplicable al texto agustiniano, porque la memoria, la inteligencia y la voluntad, si bien en cuanto tales no son "la mens", sin embargo, solo cabe entenderlas como expresiones del dinamismo interno e intrínseco de la propia "mens" $" 85$ y no como meros actos (hábitos) que se pueden o no realizar. En Agustín, la mente y su dinamismo no se puede separar de sus actividades; es sus actividades $^{86}$; el ser del hombre es vida en acción, dinamismo ${ }^{87}$.

"Persona es ante todo el carácter de la sustantividad humana" 88 . Y en su última obra, escribía X. Zubiri: "Ser persona, evidentemente, no es simplemente ser una realidad inteligente y libre. Tampoco consiste en ser sujeto de sus actos. La persona puede ser sujeto pero es porque ya es persona, y no al revés. También suele decirse que la razón formal de la persona es la subsistencia. Pero yo no lo creo: la persona es subsistente ciertamente, pero lo es porque es suya. La "suidad" es la raíz y el carácter formal de la "personeidad" en cuanto tal. La personeidad es inexorablemente el carácter de

${ }^{83}$ X. Zubiri, o.c., 135 ,

${ }^{84}$ Ibíd. 88ss.

85 "Siempre es un dislate, dice el doctor Angélico, confundir el acto o hábito con la esencia del alma (De spir. creat. a. 11 ad 1). De hecho, Agustín considera en distinto nivel de "imago Dei Trinitatis" el "recordar, entender y amar", que "la memoria, el entendimiento, y la voluntad". La primera trinidad es como la preparación para la segunda. En la primera trinidad hay un hábito o un acto; en esta, una sustancia. Aquella es menos perfecta; esta, más evidente -evidentior trinitas- como imagen de la Trinidad soberana (san Buenaventura: In I Sent. D.3, p.2 a.2 q.3). Cualquiera puede ver vigorosamente en su mente "haec tria" instituidas por Dios, que son un bien tan grande que puede "recoli, conspici, concupisci" la naturaleza eterna e inmutable; pues se la recuerda por la memoria, se la contempla por la inteligencia y se la abraza por el amor, descubriendo así la imagen de la trinidad... Si en el hombre consideramos su mente, su conocimiento (noticia) y su amor (dilección), o su memoria, inteligencia y voluntad, ninguna parte de la mente recordamos si no es por la memoria, ni comprendemos (entendemos) sino por la inteligencia, ni amamos sino por la voluntad" (Tr. 15,7,12). Hay "haec tria", realidades distintas de una misma relación que se oponen recíprocamente y al mismo tiempo se implican entre sí (Luis Arias, 57).

${ }^{86} \mathrm{DSA}, 87$.

${ }^{87}$ Argimiro Turrado, a.c., 30. Todo acto reflejo o todo hábito adquirido es algo accidental. Mientras que las relaciones de la mente de entender, amar..., le son intrínsecas. La mens no puede dejarse de recordar, entender y amar.

${ }^{88}$ Blanca Castilla, o.c., 152. 
una realidad subsistente en la medida en que esta realidad es suya. Y si su estructura como realidad es subjetual, entonces la persona será sujeto y podrá tener caracteres de voluntad y libertad. Es el caso del hombre"

\section{RESUMEN CRÍTICO ANTE ESTA POLÉMICA}

Tanto la interpretación escolástico-tomista como la zubiriana están desviadas en punto a la substancia. Hay que negar que se trata de meros actos (hábitos), sino del dinamismo (actividad), relación, y que no son consustanciales sino consustantivos, porque no se trata de que la "mens" sea una sustancia (sub-stare) sino una subsistencia (sub-sistere) a la cual le son constitutivas sus actividades. Por tanto, no tiene lugar la "inherencia sustancial", ni "haec tria" están en la "mens" como en un sujeto ${ }^{90}$.

El entendimiento -ego intellego-, la memoria-ego memini-, el amor - ego diligo-, solo se pueden entender como actos (hábitos) en tanto expresiones de su dinamismo consustantivo, no como meros actos o hábitos. $\mathrm{Y}$ en el caso particular de X. Zubiri, no se comprende bien por qué dice que la diferencia entre el yo y sus "haec tria" se difumina partiendo del sentido que del yo como sujeto da Descartes, después de afirmar que "tal cosa jamás hubiera dicho Agustín"91. Y sobre todo, no se puede aceptar la consecuencia: "que ese yo-sujeto agustiniano sea un puro yo vacío carente de las estructuras psicobiológicas, o que a lo sumo cumple con las condiciones o instrumentos intrínsecos con que el yo-sujeto ejecuta física y empíricamente sus actos..." ${ }^{\prime 2}$. En Agustín nada hay más constitutivo de su yo personal que "ser sí mismo", nada hay más propiamente mío que mi querer y mi voluntad con lo que ello implica de responsabilidad y libertad

${ }^{89}$ X. Zubiri, El hombre y Dios, Alianza, Madrid 1985, 49.

${ }_{90}$ Parece claro que Agustín, particularmente cuando habla de sustancia en el De Trinitate, la entiende, más bien, como subsistentia (natura o essentia). Y por eso es que no entiende la "mens" como sujeto sustentante de "haec tria", bien se trate de "mens, amor et notia eius" (primera trinidad), bien de "memoria, intellectus et voluntas" (segunda trinidad). Y tal vez sea por la misma razón que nunca use términos como "facultad o potencia" con el sentido de la escolástica, para referirse a esta triple realidad relacional (cf. Tr. 5,5,6; 5,9,10;9,4,5.

${ }^{91}$ X. Zubiri, Sobre el hombre, 107; J.A. Galindo Rodrigo, a.c., 415-19.

${ }^{92}$ Ibíd. 
existencial, "eres dueño de ti mismo"93. Viene a ser, aunque con distinto lenguaje, lo que X. Zubiri entiende por "suidad". "La suidad es la raíz y el carácter formal de la "personeidad" en cuanto tal. La personeidad es inexorablemente el carácter de una realidad subsistente en la medida en que esta realidad es suya. Y si su estructura como realidad es subjetual, entonces la persona será sujeto y podrá tener caracteres de voluntad y libertad.

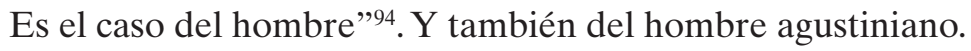

Desviada está así mismo, por doble capítulo, la interpretación moderna-agustiniana: al no entender que la "mens" y "haec tria" admiten considerarse en sí y en cuanto tales y al no tener suficientemente en cuenta la relación tensional y dinámica entre el todo y las partes, entre "la mens y sus "haec tria". Cuando todas y cada una mutuamente se comprenden, existe igualdad entre el todo y la parte, y las tres son unidad: una vida, una mente, una esencia" 95 , pero "haec tria son distintas, "con oposición recíproca". Ciertamente no hay "mens" sin "haec tria", ni "haec tria" sin "mens", porque la estructura de "la mente humana jamás puede dejar de recordarse, amarse y conocerse" ${ }^{\prime \prime}$.

\subsection{Más allá y más acá de toda polémica: El hombre "creado a imagen y semejanza de la Trinidad"}

Agustín, una vez que asentó con toda garantía el misterio trinitario, descubre, recogido en su interior, la imagen de la estructura trinitaria del hombre. La dialéctica entre el "esse in" y el "esse ad", tomada del misterio trinitario, nos acerca al también misterio de la persona humana y, desde luego, nos indica que el camino para ser fieles al pensamiento agustiniano será contemplarlo siempre a la luz trinitaria reflejada (impresa) en la interioridad de la mens. Al modo cómo las personas divinas son relaciones sub-

${ }^{93}$ Conf. 8,8-10; LA. 2,18-20; 3,3,7-8; 3,6,19.

${ }^{94} \mathrm{X}$. Zubiri, El hombre y Dios, 49.

${ }^{95} \operatorname{Tr} .10,11,18 ; 10,12,19 ; 14,4,6-7 ; 14,6,8-9$.

${ }^{96}$ Ibíd. 10,3,5: “...imposible un desconocimiento absoluto del yo, porque si sabe que no sabe, se conoce, y si ignora que se ignora, no se busca para conocerse. Por el mero hecho de buscarse ¿no prueba ya que es para sí más conocida que ignorada?”. La mente no se conoce o se ama en parte, sino totalmente, porque es toda el alma la que conoce, ama... (Ibíd. $9,4,6)$. 
sistentes, en unidad de "aseidad" 97 , así "haec tria", triple relación: memoria, inteligencia y voluntad, constituyen unidad consustantiva con la mente, pero "haec tria", al no ser relaciones subsistentes, forman una sola persona.

La antropología dialéctica de Agustín nos hace concordar en unidad lo igual y lo distinto entre "mens" y "haec tria", si ubicamos cada texto en su tiempo y respectivo nivel de reflexión. Son idénticos y son distintos, no separados ni separables. Aplicando aquí el consabido apotegma atanasiano: "Neque confundes personas, neque substantiam separantes" (Symb. Athan.), podríamos afirmar: "Neque confundentes haec tria, neque mentem separantes". "Haec tria" en sí mismos son una sustancia, iguales en naturaleza, pero en cuanto proyección "ad aliud" son distintos, porque dicen mutua oposición relativa (relativamente, no sustancialmente) ${ }^{98}$.

Exactamente la mente, sabiéndose particionera del "esse in - esse ad aliud" trinitario, "contempla cómo en ella se opera un misterioso conjugar dialéctico entre "opuestos": inmortal-mortal, inmutable-mutable, simplecompuesto, espiritual-corporal, eterno-temporal, de modo analógico a como se opera en Dios la unidad entre la aseidad y la trinidad de personas. Decimos de modo analógico, porque el hombre no es de la misma naturaleza de Dios, pero está hecho a su imagen y semejanza; y propio de la imagen es ser una estructura remisiva que solo se puede entender como referida al modelo del que es imagen ${ }^{99}$. Siendo criatura, no está hecha únicamente a semejanza (huella, vestigio) como el resto de las cosas creadas en las cuales "todo lo que no se predica según la sustancia, se predica según los accidentes" ${ }^{100}$, y donde se agota en pura contingencia y mutabilidad, sino que está hecha "a imagen de la Trinidad", referida en particular a la naturaleza de su "mens" que, según hemos dicho arriba, ocupa un nivel (lugar) medio, verdadero "metaxy” ontológico y axiológico entre el creador y las criaturas corpóreas-materiales ${ }^{101}$, entre lo inmutable y lo mu-

${ }^{97}$ Ibíd. 14,8,11.
${ }^{98}$ Ibíd. 9,6,7; 5,8,9.
${ }_{99}$ A. Pieretti, Doctrina Antropológica Agustiniana: a.c., 358.
${ }^{100}$ Tr. 5,5, 6,
${ }_{101}$ Ep. 18, 2: "Est natura per locos et tempora mutabilis, ut corpus, et est natura per locos nullo modo, sed tantum per tempora etiam ipsa mutabilis, ut anima, et est natura, quae nec per locos nec per tempora mutari potest, hoc Deus est...Summum illud ipsa beatitas; infimum, nec beatum nec miserum potest esse; quod vero medium, vivit inclinatione ad infimum miserere, conversione ad summum beate vivit...., atque ita summo inhaerere fit idoneus". 
table. Pues en tanto "imagen" participa de ambas condiciones: la de ser "capax Dei", inmortal, inmutable y simple, y la de ser mortal, mutable y compuesto, por su procedencia "ex nihilo".

El hombre recogido en su interior, al saberse consciencia y presencia de sí, "memoria sui-intellectus sui-amor sui”, contempla esta su doble condición natural, ser mutable-contingente e inmutable: "dentro de ti mismo, en el hombre interior reside (habita) la Verdad; y si hallares que tu naturaleza es mudable trasciéndete a ti mismo y al remontarte sobre las cimas de tu ser, te elevas sobre tu mente..." "102. En nuestra mente están impresas las verdades eternas en forma de nociones (o preconocimientos) de felicidad, sabiduría, orden, justicia..., reglas supremas que están en nosotros sobre nosotros, y nos constituyen ${ }^{103}$. Constituyen nuestra apertura trascendental: vemos en la verdad, no vemos la verdad; vemos en la luz, no vemos la luz. Desde el propio recuerdo presencial o "memoria sui" descubro en mí el recuerdo presencial o "memoria Dei" ${ }^{104}$, y descubro que esa doble relación presencial me constituye: "no sería si Tú no estuvieses en mí, o mejor, yo no sería si no estuviese en Ti” "105, "intimo meo et summo meo" 106 . “Dónde te hallé, pues, para conocerte sino en Ti sobre mí?" 107.

En la "memoria sui" se encuentra el dinamismo que le hace superarse a sí misma en su tendencia hacia la "memoria Dei" al mismo tiempo que le hace consciente de su propia contingencia y mutabilidad. La "memoria sui" contiene las condiciones a priori que hacen posible la misma actividad consciente ${ }^{108}$. "A la capacidad que la mens tiene de estar presente para sí misma, la llamamos "memoria sui" (presencia y recuerdo de sí misma), y cuando piensa en sí y se ama, se unen memoria e inteligencia" ${ }^{109}$. La "memoria sui" y la "memoria Dei", distintas e inseparables, constituyen la na-

${ }^{102}$ VR. $39,72$.
${ }^{103} \operatorname{Tr} .8,9,13$.
${ }^{104}$ Conf. $10,17,26 ; 10,24,35$.
${ }^{105}$ Ibíd. 1,2,2.
${ }^{106}$ Ibíd. 3,6,11.
${ }^{107}$ Ibíd. 10,26,37.
${ }^{108}$ L. Cilleruelo, "La memoria sui”, Giornale di Metafisica IX (1954) 478-492; Id, "San Agustín y Kant”, Religión y Cultura IV (1959) 187-211.

${ }^{109} \operatorname{Tr}$. 14,11,14. "La memoria es el contenido del espíritu (mens) como acto intelectual”: M.F. Sciacca, San Agustín. Barcelona, 1955, cf. L. Arias, en nota 3 al De Trinitate (Tr. $15,7,11)$. 
turaleza de la mens ${ }^{110}$, siempre presentes en la "mens", aunque no siempre presentes a la "mens"; se descubren ambas como nociones a priori, preconceptuales en relación a cualquier conocimiento actual y transitorio. Pero es desde la "presencia de sí" o "memoria sui", que se activa la presencia o "memoria Dei-intellectus Dei-amor Dei (voluntas Dei)", y se realizan los conocimientos actuales, transitorios y que, almacenados en la "mens", van a constituir la "memoria psicológica".

"El alma (mens) siempre y totalmente se recuerda, se conoce y se ama"111. "Nada hay tan presente a la mente como la mente misma" ${ }^{112}$. La mens, reflexionando sobre sí, con la mirada que ella tiene de sí misma, se forma el concepto de sí y se percibe en su estructura trinitaria: se da cuenta de que, además de ser memoria de sí, es inteligencia de sí y amor de sí113. La "memoria sui-intellectus sui-amor sui" sirve de centro y puente entre la "memoria Dei-intellectus Dei-voluntas Dei" y la memoria psicológica ${ }^{114}$. La "memoria sui "guarda un cierto paralelismo con la "memoria Dei", siendo esta la que hace posible aquella, y aquella la que suscita a esta. La "memoria Dei" constituyente de la naturaleza humana, junto con la "memoria sui", tienen una estructura ontológica de carácter trascendental cuyo conocimiento (mejor noción) es permanente, irreflejo, atemático y a priori: y la memoria psicológica, que se nutre de la experiencia interior y exterior, es conocimiento explícito, reflejo, temático y a posteriori ${ }^{115}$.

Con estas anotaciones por base, podemos entender la dialéctica agustiniana entre la "mens" y sus relaciones sin incoherencia o contradicción

${ }^{110}$ Ibíd. 9, 6-7. Cf. J. Pegueroles, San Agustín. Un platonismo cristiano, Barcelona 1985, 214-19. B.L. Zekiyan, "Illuminazione e memoria Dei in S. Agostino", Congresso internazionale su S. Agostino, II, Roma 1987, 411.

${ }^{111}$ Ibíd. 10,3-4; 10,10,13-14; 14,8,11.

112 Ibíd. 10,7,10.

113 Ibíd. 14,6,9.

114 Ibíd. 12,12,17; Div. q. 83,46.

${ }^{115}$ Lope Cilleruelo, "La memoria Dei según san Agustín”, Aug. Mag. Paris, 1994, 499509; Ibíd. "Pro memoria Dei”, Études Augustiniennes 12 (1966) 65-84. K. Winkler, "La théorie augustiniennes de la mémoire á son point de départ", Aug. Mag. Paris 1954. V. Capanaga, "La estructura ontológica de la memoria Dei”, Estudio Agustiniano 12 (1977) 369-92. J.A. Galindo Rodrigo, "La inteligencia humana ante Dios", en: J. Oroz Reta - J.A. Galindo Rodrigo, El pensamiento de San Agustín para el hombre de hoy. I. La Filosofía Agustiniana, Edicep, Valencia 1998, 532. 
alguna. Las relaciones, son en sí mismas una con la mente, pero distintas en cuanto realidades relacionales (relativas). ¿Hay contradicción entre Dios vida-espíritu, ser absolutamente absoluto, inmortal, infinito, eterno, simple, y la criatura absolutamente relativa, corpórea, mortal, finita, temporal, compuesta? De hecho, la persona humana es el término medio cuya constitución conjuga misteriosamente esos extremos como realidad relacional intermedia (metaxy), ser relativamente absoluta: ser inmortal-mortal, eterno-temporal, simple-compuesto, mutable-inmutable, espíritu-materia. En fin, somos ambas realidades opuestas sin que seamos plenamente ninguna de ellas.

En la dialéctica al modo agustiniano, la mens constituida "a imagen de Dios ${ }^{116}$, y en cuanto imagen de Dios, es inmortal porque la Verdad eterna le da el ser117. "El Dios inmortal mismo ha hecho a su imagen la mens inmortal"118. "La mens, efectivamente, es capaz de la naturaleza suma y puede ser partícipe de ella. En la mens creada a imagen del Creador, se ha de buscar injertada inmortalmente en la inmortalidad de Dios" $" 119$.

Si la mente humana es inmortal-espiritual, también lo serán sus habitudes o relaciones "memoria, entendimiento y voluntad", constituidas como "co-partícipes" de la imago Trinitatis", y por tanto la "mens" no podrá ser entendida como substancia en el sentido estricto de "sub-stare", sino de "sub-sistere", ni "haec tria" podrán ser considerados accidentes. Por otra parte, las habitudes, relaciones o movimientos: memoria, inteligencia y voluntad, junto con la mente, son mutables porque son susceptibles de la verdad y de la falsedad, del bien y del mal ${ }^{120}$. Mientras la criatura corpórea es múltiple -mutable y no simple-, la criatura espiritual (la mente), es simple en cuanto "imago Dei" 121 , pero mutable por sus afectos-quereres. Así, por ejemplo, la virtud o poder de la voluntad afectada por la luz a la que nada afecta ${ }^{122}$, perteneciendo a la misma naturaleza del

\footnotetext{
${ }^{116} \operatorname{Tr} .12,7,10$; LA. 3,25,74.76.

${ }_{117}$ Inm. An. 8,15; $12,19$.

${ }^{118}$ Quant.an. 2,3.

$119 \operatorname{Tr} .14,4,6$.

120 S. 65,4-5; Sol. 2,3,4.

${ }^{121}$ VR. 10,18; 30, 54-56; An. et eius orig. 1,4,4.

122 S. 341,8; 150,9 .
} 
ánimo (mens), se siente afectada por la diversidad de sus quereres ${ }^{123}$. El alma es simple y múltiple (compuesta) ${ }^{124}$; es simple, pero no igual a la simplicidad de Dios, y es mutable porque tiene diversos sus quereres (voluntades), afecciones ${ }^{125}$. El apartado siguiente especifica otro aspecto más de estos puntos de nuestra crítica.

\subsection{Los términos "homo" $y$ "persona" tienen diverso alcance}

Los términos "hombre" y "persona" significan lo mismo, "de modo que el hombre es persona y la persona es hombre", afirma J.R. Sanabria ${ }^{126}$. Sin embargo, esta apreciación no se corresponde con la realidad ni con la mente de san Agustín. De hecho, cuando queremos precisar los conceptos, encontramos diferente alcance de sentido entre "homo" y "persona". "Agustín, incluso considerando admisible la noción clásica de hombre como "animal racional-mortal", al fijar su mirada en la trinidad divina de las personas, no define la realidad de la persona humana por su "naturaleza (substancia)" sino por aquello que descuella en el hombre como es su "mens" con su triple relación, que hace que el hombre sea "a imagen de Dios". "Encontramos una trinidad en el hombre: "la mente, la noticia que lleva a su conocimiento y el amor con que se ama", o aquella otra de más alto relieve trinitario -"evidentior trinitas"-: "memoria, inteligencia y voluntad"127.

Claramente expresa Agustín que cada hombre es una persona, pero especifica que esta reside, no en el hombre en general sino en la "mens":

${ }^{123}$ CD. 5,11; 9,4-5; 14,9,2-6; Tr. r. 4,5; 15,7,11; Conf. 13,32,47; LA. 3,17,49. Cf. In Io. Ev. 46,8. "Virtus est animi habitus naturae modo atque rationi consentaneus" (Div. q. 83, 36,1$2 ; L A .2,18-19)$. Habitus algo que se adquiere por la práctica y se puede perder (Div. $q$. $83,73,1)$. La potencia del alma -de animae potentia- puede realizar todos sus actos simultáneamente..., yendo gradualmente hacia arriba...hasta llegar a la contemplación”. La mens es inmortal si es por sí misma. Pues lo que es por sí mismo, es necesariamente incorruptible (Inm. an. 8,15; 11,18). El ser que el ánimo recibe de un principio que no admite realidad contraria, no puede ser arrebatado por causa alguna. Por ende, el ánimo no puede perecer" (Ibíd. 12,19).

${ }^{124} \operatorname{Tr} .6,6,8$.

${ }^{125}$ Conf. 8, 8-10; Div. q. 83, 38-40, nota 150 (se dice que la voluntad no es de la naturaleza del alma); 83,7 .

126 José Rubén Sanabria, Filosofía del hombre (Antropología filosófica), Porrúa, México 1987, 235.

${ }^{127} \operatorname{Tr} .15,6,10 ; 15,3,5 ; 15,7,12 ; 10,11,17-18$. 
"Sed haec tria ita sunt in homine, ut non ipsa sint homo. Homo est enim, sicut veteres definierunt, animal rationale mortale. Illa ergo excellunt in homine, non ipsa sunt homo. Et una persona, id est singulus quisque homo, habet haec tria in mente". "Si enim mentem recte dicimus principale hominis, id, est, tanquam caput humanae substantiae, cum ipse homo cum mente sit homo" (siendo el hombre sólo por su mente hombre) $)^{128}$.

El hombre (interior) es persona por (con) su mente. "El hombre exterior, dotado de cuerpo sensible, se le llamaría sin motivo hombre de no ofrecer alguna semejanza con el hombre interior (inest ei similitudo)"129. El hombre es hombre "adiuncto corpore" (por la adición de su cuerpo), pero "retracto ergo corpore", permanece la "mens"

Si definimos al hombre como una substancia racional que consta de alma y cuerpo, indudablemente que el hombre posee un alma que no es cuerpo y un cuerpo que no es alma. De modo similar, decimos que "illa tria" no son el hombre sino del hombre, o que están en el hombre. Si pensamos solo en el alma, la mente es algo (una porción) de ella, como la cabeza, el ojo... son algo del cuerpo. La mente no es el alma sino lo que en el alma descuella. He aquí por qué cada hombre individual es imagen de Dios, "non secundum omnia quae ad naturam pertinent eius, sed secundum solam mentem, imago Dei dicitur, una persona est, et imago est Trinitatis in mente" 131 .

Hombre-ser humano- tiene sentido general de especie, mientras que persona significa algo singular e individual. "Persona es término genérico e incluso se aplica al hombre, que puede ser llamado persona a pesar de la distancia que media entre el hombre y Dios", porque ser la cualidad de persona es común a todos los hombres ${ }^{132}$. Caben dos sentidos del concepto de persona: sentido primario aplicado a la Trinidad y sentido derivado o

${ }^{128} \operatorname{Tr}$. 6,9,10. Usando la figura retórica de sinécdoque.

${ }^{129}$ Ibíd. 11,1,1. El hombre exterior, i.e., según el cuerpo, está hecho "a semejanza de Dios", y "a imagen de Dios", según el hombre interior, i.e., según la "mens" (Div. q. 83,51,14).

${ }^{130}$ Ibíd. 9,2,2: "Retracto enim eo quod homo est quod homo adiuncto corpore dicitur; retracto ergo corpore, mens et spiritus manet".

${ }^{131}$ Ibíd. 15,7,12;14,8,11. "La mente, decimos con razón, es la parte principal del hombre, siendo el hombre solo hombre por su mente" (Tr. 6,9,10).

132 Ibíd. 7,4,7-8. 
impropio aplicado al hombre. El derivado puede tener, a su vez, una doble acepción: aquella que distingue al ser humano de los demás seres y aquella que hace que cada individuo sea una persona única y diferente de todos los demás de su especie ${ }^{133}$. Cuando decimos "homo" designamos una substancia ${ }^{134}$, mientras que cuando decimos "persona" hablamos de (indicamos) relación, habitud (refero-referetur) ${ }^{135}$. Y de modo análogo como en Dios distinguimos la "essentia" o naturaleza de las personas, así en el hombre hemos de distinguir naturaleza y persona: "Una persona, es decir, cada hombre individual, tiene en su mente estas tres cosas, que no son el hombre, sino del hombre, o están en el hombre. Cada hombre individual, según sola la mente (secundum solam mentem) es imagen de Dios, no según toda la plenitud de su naturaleza; y es una persona y en su mente está la imagen de la Trinidad" 136 . La persona humana está hecha "a imagen de la Trinidad entera, no de una persona particular de la Trinidad"137."Faciamus hominem ad imaginem nostram. Quod ex persona ipsius Trinitatis rectissime accipitur. Tria itaque ista in hominis anima cogitemus: memoriam, intellegentiam, voluntatem; ab his tribus fit omne quod facimus... Omne igitur opus nostrum ab his tribus fit: nihil enim agimus, quod non haec tria simul agant"138.

"Si ser es término absoluto, persona lo es relativo. Cuando defino al hombre, término específico, comprendo en la definición a todo individuo de la especie humana y no existe elemento específico que no se encuentre en el hombre"139. Cuando decimos "homo" designamos una substancia, mientras que cuando decimos "persona" hablamos de (indicamos) relación, habitud (refero-referetur) ${ }^{140}$. Y de modo análogo a como en Dios distinguimos la "essentia" o naturaleza de las personas, así en el hombre hemos de distinguir la naturaleza humana de la persona en cuanto existencia singular mental. "Nosotros mismos somos animi (nosque ipsi animiánimos-mentes simus), pero no sensibles, es decir, cuerpos, sino inteligi-

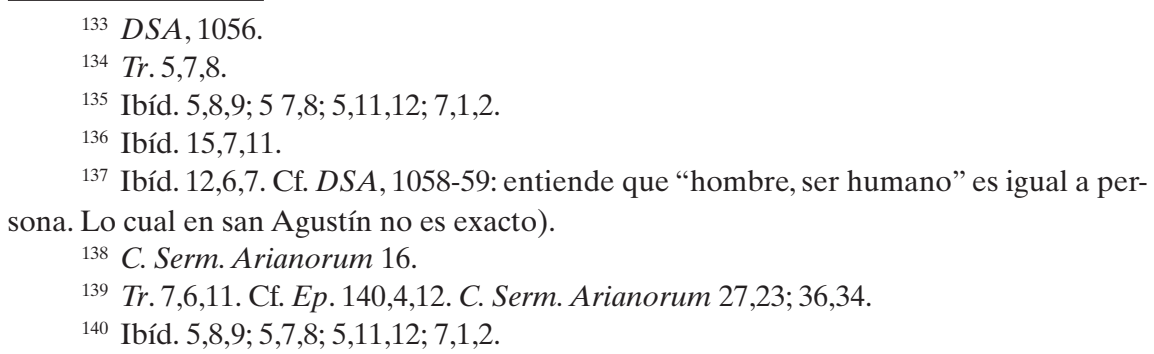


bles, pues somos vida" ${ }^{141}$. Estamos hechos a imagen de Dios en cuanto a la "mente racional", no en cuanto al cuerpo. En cuanto al cuerpo estamos hechos "a semejanza de Dios"142.

\section{CONCLUSIÓN}

La persona se define constitutivamente por su relación religada. "La naturaleza toda, para Agustín, tanto la de los seres materiales como la de los espirituales, proclama una estructura (huella) trinitaria: "modus, species, ordo"143. Y X. Zubiri habla de "la creación, que tiene una estructura formalmente trinitaria" ${ }^{144}$. Pero la naturaleza del hombre, de ese magnum miraculum como lo llama Agustín ${ }^{145}$, plasma la "imago Dei trinitatis" de las personas divinas con su "esse (meminere), intellegere, amare" y muy particularmente en su "mens": "memoria, inteligencia, y voluntad"146.

Esta trinidad goza de dinamismo estructural con su triple relación: “capax Dei, indigens Deo, particeps Dei"147. Relación-relatividad-respectividad, o "habitud trinitaria" que es constitutiva religación como "particeps Dei", tanto por su capacidad de absoluto (del Absoluto), como "indigens Deo" por su indigencia del Absoluto. "Yo soy un absoluto de un modo relativo" nos ha dicho X. Zubiri. Y esta relatividad-respectividad es la religación, o relación religada ${ }^{148}$.

"La religación es una dimensión constitutiva de la persona humana. La religación no es una teoría sino un hecho inconcuso"149; "es la raíz misma

${ }^{141}$ Ibíd. 11,1,1.

${ }^{142}$ Ibíd. 14, 16, 22;15, 7,11;14,8,11; Div. q. 83,51; Gen. ad litt. 6,12,22.

${ }^{143}$ V. Capánaga, "Intr. Gen. a las Obras Completas de San Agustín”, Tom. I, BAC, Madrid 1979, 46-57; CD.11,24; VR. 7,13; Gen. ad litt.i. o. 1,2; Gen. ad litt. 9,15,26; An. et eius orig. 3,22; Ench. 10,3.

${ }^{144}$ X. Zubiri, El problema teologal, 177; X. Zubiri, Estructura dinámica de la realidad, 56; Ibíd. 119.

${ }_{145}$ S. 126, 4: El hombre admirador de las maravillas de las obras de Dios, "cum sit ipse mirator magnum miraculum". Div. q. 83, 51,2.

${ }^{146} \operatorname{Tr} .10,11,17-18$.

147 Ibíd. 14,4,7;14,8,11. Cf. Sol.1,1,4-5; CD. 12,1,3.

${ }^{148}$ X. Zubiri, El Hombre y Dios, Alianza, Madrid 1985, 101.

149 Ibíd. 374. 
de mi Yo, de esta vida personal mía... es la raíz de mi ser"150 "Dios tiene que ser el fundamento del poder de lo real. Por tanto, es eo ipso un fundamento último, posibilitante e impelente ${ }^{151}$. Esta fundamentalidad es presencia de Dios en las cosas, presencia formal e intrínseca, es presencia transcendente, transcendente en las cosas y constituyente de las cosas ${ }^{152}$. El espíritu (mens) se despliega constitutivamente como movimiento "intensio-intentio-extensio" desde sí mismo hacia la transcendencia y hacia la temporalidad: "Si encuentras mudable tu naturaleza, trasciéndete también. Pero recuerda que, cuando te trasciendes, trasciendes tu propio principio vital raciocinante y tiendes hacia donde se enciende la luz misma de la razón"153. "No sería en modo alguno si tú no estuvieses en mí, o mejor, si no estuviese en ti"; "te hallé en ti sobre mí...; todas las cosas, si no estuviesen en ti, no serían" 154 ."Yo no sería si Tú no fueses en mí sobre mí". "Tú estabas dentro de mí, más interior que lo más íntimo mío y más elevado que lo más sumo mío"155. "En Dios somos, nos movemos y existimos" (Pablo, Hech 17,28).

El hombre-persona es ser religado, relación religada, porque no tiene en sí sino en otro el fundamento ontológico propio ${ }^{156}$; tiene por meta de toda su dialéctica racional alcanzar la fuente de la luz y de la verdad"157. Así lo entendieron los mejores filósofos de todos los tiempos que han gastado su talento y sus esfuerzos investigando las causas de las cosas por el conocimiento de Dios, descubriendo dónde estaba la causa del mundo creado, la luz de la verdad y la fuente de la felicidad: “...ubi esset causa constitutae universitatis, et lux percipiendae veritatis, et fons bibendae felicitatis"158. "Toda vida racional, si es perfecta, obedece a la verdad eterna

${ }^{150}$ Ibíd. 128. "La religación es la dimensión radical de mi realidad sustantiva en cuanto persona, esto es, en cuanto construye su Yo, su ser" (Ibíd. 156). Hay que partir de la religación como hecho total, es el acontecer del poder de lo real, que es tanto como decir que es formalmente y "a una" algo humano y cósmico" (Ibíd. 129).

151 Ibíd. 130.

${ }^{152}$ Ibíd. 174 ss. Cf. X. Zubiri, El problema teologal, 56ss.; S. Agustín, Conf. 7,14-17; 10,6,8-10; In Io. Ev. 20,11-12.

${ }^{153}$ VR. 39,72. Cf. en. Ps. 130,12; 103,4,2.

${ }^{154}$ Conf. 1,2,2; 5,2,2;10, 26-27; VR. 11,22; en. Ps. 118,22,6; 41,8.

155 Ibíd. 3,6,11.

${ }^{156}$ VR. 5,8; 7,12-13.

${ }^{157}$ Ibíd. 39,72.

${ }^{158}$ CD. 8,10,2; Sol.1,6,12;1,8,15. Así lo constatan tantos y tantos filósofos desde la antigüedad. Cita Agustín, a pitagóricos, itálicos, indos, egipcios, persas, caldeos, libios, galos, 
que en lo íntimo nos habla sin estrépito" 159 .Él es la fuente de nuestra felicidad, Él es el fin de nuestros deseos. Eligiéndole, o mejor, reeligiéndole, tendemos a Él por el amor, para en llegando, descansar. Seremos felices precisamente por ser perfectos con el fin" ${ }^{160}$.

escitas, hispanos... y muy en particular a los platónicos que reconocieron a Dios como "lux cognoscendarum, et bonum agendarum; principium naturae, et veritas doctrinae, et felicitas vitae" (cf. $C D$. 8,9-10. "Deus causa ómnium naturarum, causa subsistendi, rerum Auctor, creaturarum effector, causa constitutae universitaris, origo, causa naturae" ( $C D$. 8,4; 8,8.).

${ }^{159}$ VR. 55,110.

${ }^{160} C D .10,3,2$. 